\title{
HIGH DENSITY AIRBORNE LIDAR ESTIMATION OF DISRUPTED TREES INDUCED BY LANDSLIDES
}

\author{
Khamarrul Azahari Razak ${ }^{(1,2,5)}$, Alexander Bucksch ${ }^{(3)}$, Menno Straatsma ${ }^{(4)}$, Cees J. Van Westen ${ }^{(2)}$, \\ Rabieahtul Abu Bakar ${ }^{(4)}$, Steven M. de Jong ${ }^{(5)}$ \\ 1) UTM Razak School of Engineering and Advanced Technology, Universiti Teknologi Malaysia, \\ Jalan Semarak, 54100 Kuala Lumpur, Malaysia \\ ${ }^{2)}$ Faculty of Geo-Information Science and Earth Observation, University of Twente, \\ Enschede, P.O Box 217, 7500AE, The Netherlands \\ ${ }^{3)}$ School of Biology and School of Interactive Computing, Georgia Institute of Technology, \\ Atlanta, Georgia, United States of America \\ 4) Southeast Asia Disaster Prevention Research Institute, Universiti Kebangsaan Malaysia, Malaysia \\ 5) Utrecht University, Department of Physical Geography, Utrecht, The Netherlands
}

\begin{abstract}
Airborne laser scanning (ALS) data has revolutionized the landslide assessment in a rugged vegetated terrain. It enables the parameterization of morphology and vegetation of the instability slopes. Vegetation characteristics are by far less investigated because of the currently available accuracy and density ALS data and paucity of field data validation. We utilized a high density ALS (HDALS) data with 170 points $\mathrm{m}^{-2}$ for characterizing disrupted vegetation induced by landslides by means of a variable window filter and the SkelTre-skeletonisation. Tree analyses in landslide areas resulted in relatively low height, small crown and more irregularities, whereas these peculiarities are not so obvious in the healthy forests. The statistical tests unveiled the clear differences between the extracted parameters in landslide and non-landslide zones and supported the field evidences. We concluded that HDALS is a promising tool to geometrically retrieve disrupted woody vegetation structures and can be good bioindicator to landslide activity.
\end{abstract}

Keywords - Landslide activity assessment, Forested landslides, SkelTre-skeletonization, TreeVaw, Bois Noir

\section{INTRODUCTION}

In mountainous regions, landslides pose a significant impact to forest disturbances and have long been recognized as an effective agent for modifying the hillslope morphology. Combined with anthropogenic activities, especially the developments of unstable tropical terrain, landslides as natural processes have become natural disasters [1].

Modern remote sensing approaches have revolutionized the landslide hazard and risk assessment in mountainous landscapes. Remote sensing enables the parameterization of morphology, vegetation and drainage conditions of the slopes [2]. However little attempt has been made to utilize the ALS data to represent tree structures that may be indicative of landslides, because the required high point density, the error in ALS data and limited capability of passive remote sensing instruments to detect variability of 3D-forest-structure [3].

Woody vegetation can be an indicator of local deformation and different epochs of displacement [4]. These methods, however, are time consuming and required an intensive field investigation. Despite the advantages of airborne laser scanning (ALS) data to recognize the landslide morphological features beneath dense forests [5; 6], less attention is given to fully examine the ALS data representing the vegetation structures for landslide mapping under forest. The performance of ALS data for measuring and assessing the physical presence of disrupted trees and its relation to landslides remains unexplored.

The presented study aims at providing better insight into the use of high density ALS (HDALS) data to characterize disrupted trees induced by landslides. ALS-derived irregular trees are parameterized by physical presence of tree deformations associated to bioindicator of landslide activity such as the dissimilarities of tree height and the single tree irregularities (tree inclination and orientation).

\section{STUDY AREA}

The Bois Noir catchment is located on the north-facing slope of the Barcelonnette Basin in the South French Alps (Alpesde-Haute-Provence, France). Altitude of the study area is up $2100 \mathrm{~m}$ above mean sea level. The area is characterized by irregular topography with slope gradients ranging between 10 and $70^{\circ}$ [7]. This forested catchment is situated in the dry intra-Alpine zone with a Mediterranean environment and is 
characterized by strong inter-annual rainfall variability. Rainfall intensity can over pass $50 \mathrm{~mm} \mathrm{~h}^{-1}$ especially during summer storms [8]. Geologically, the area is characterized by morainic colluvium and autochthonous CallovoOxfordian unstable black marls, overlaid by deposits of reworked glacial till and is highly affected by landslides [8;9]. The hummocky topography is inherited from the different phases of the Quaternary glaciation [10].

The forestland in the Ubaye Valley was seriously affected by the population pressures and soil erosion in the $15^{\text {th }}$ and $16^{\text {th }}$ centuries. However, in the $19^{\text {th }}$ century reforestation was started, e.g. the enforcement of local laws [11]. It is mainly comprised of Pinus uncinata Mill. Ex Mirb (mountain pine), Pinus sylvestris (Scotch Pine), Laris deciduas (Larch), Picea abies (Spruce), and Pinus Nigra.

Landslides are controlled by the climatic conditions and likely occurs after relatively dry periods influenced by heavy rainfalls [8]. It was reported that this area has been identified as highly susceptible to landslides although most of the area is covered by vegetation [7]. An existing landslide inventory map of 1:10,000 scale, was created based on aerial-photo interpretation, field surveys and historical records. Tilted and deformed trees, as well as recent scarps and open cracks, clearly indicated that there is reason to believe that the Bois Noir landslide has been subjected to multiple reactivation in the recent past [12].

\section{MATERIALS AND METHODS}

\subsection{HDALS and field data characteristics}

A hand-held laser scanning system was used to capture an HDALS data in July 2009. The system consists of a RIEGL VQ-480i laser scanner, a Topcon Legacy GGD GPS and an iMAR FSAS inertial measurement unit (IMU), carried out using a helicopter flying about $300 \mathrm{~m}$ above the ground. Several flight lines were acquired over the same area to increase the point density. We used about 214 million points with a mean point density of 170 points $\mathrm{m}^{-2}$.

Field campaigns were carried out in June 2009, June 2010 and September 2011 to measure tree location, height, inclination and orientation of 560 individual trees. We applied a purposive sampling scheme to acquire structural tree attributes, because it was neither possible to collect them randomly nor systematically on a regular grid due to ruggedness of topography and poor accessibility. About $60 \%$ of field data was collected from landslide areas, the remainder was located on the stable areas nearby.

Several local geodetic stations were setup near the landslide area using a Leica differential GPS system 1200, up to a 24-hour static observation was carried out for each geodetic station. Post-processing on the GPS data was performed resulting with horizontal and vertical precision of geodetic stations are on average 8 and $13 \mathrm{~mm}$, respectively.

\subsection{Extraction of disrupted trees induced by landslides}

The estimation of tree height was done using the variable window filter (VWF) algorithm developed by [13]. The SkelTre-skeletonisation method [14] was used to determine the tree irregularity from the point clouds. Both methods were evaluated using the field data, mostly covered by 420 Pinus uncinata (75\%), 82 Pinus sylvestris (15\%) and 58 Larix decidua (10\%) collected at tree stand level in June 2009, June 2010, and September 2011.

\section{RESULTS AND DISCUSSION}

\subsection{HDALS-derived disrupted trees}

The single tree delineation using TreeVaW resulted in about 80000 individual trees with an average detection rate of 84.8 $\%$ in an old and dense unthinned pine plantations mixed with natural regeneration in the Southern French Alps.

As expected, the tree detection in the landslide areas resulted in less accurate compared to non-landslide areas. This is because in the landslide affected areas, the chaotic trees are often intermingled at the crown area and are inclined at various orientation angles. Across the study area, TreeVaW method had higher omission errors $(21.4 \%)$ as many crown maxima were not detected compared to errors in falsely recognizing the top crown. The mountain species in Bois Noir has generally irregular shape of tree crown and high tree density rate (up to 800 trees per hectare) as a result of poor forest management practices. The tree detection result presented here is within the acceptable rate as the VWF algorithm was originally developed based on coniferous forests covering a wide range of pines species with tree age up to 65 years [13].

We obtained the coefficient of determination of 0.80 for tree height. TreeVaW method was successfully estimated the tree height with RMSE of $1.426 \mathrm{~m}$. Fig. 1(a) shows the scatter plot of ALS-derived single tree heights versus tree heights from field data with an indication of 1:1 relationship line. TreeVaW mostly under-predicts the tree height, which is more prominent at lower height between 5 to $12 \mathrm{~m}$. Overall, this result is comparable to [13], who predicted dominant tree height, with $R^{2}$ value of 0.84 in the healthy forest characterized by gentle slopes.

The tree detection rate and height estimation are comparable to [13], who predicted dominant tree height, with $R^{2}$ value of 0.84 in the healthy forest characterized by gentle slopes. The accuracy of estimated tree heights was slightly lower because most of the trees were located on undulated terrain where disrupted trees and a minor amount of scattered drunken trees grow [15]. We also observed that most trees exhibit significant characteristics such as disruption, irregularity (e.g. tilting or bending) and entangled crowns. These factors have direct impact on the accuracy of tree height estimated from ALS data. 

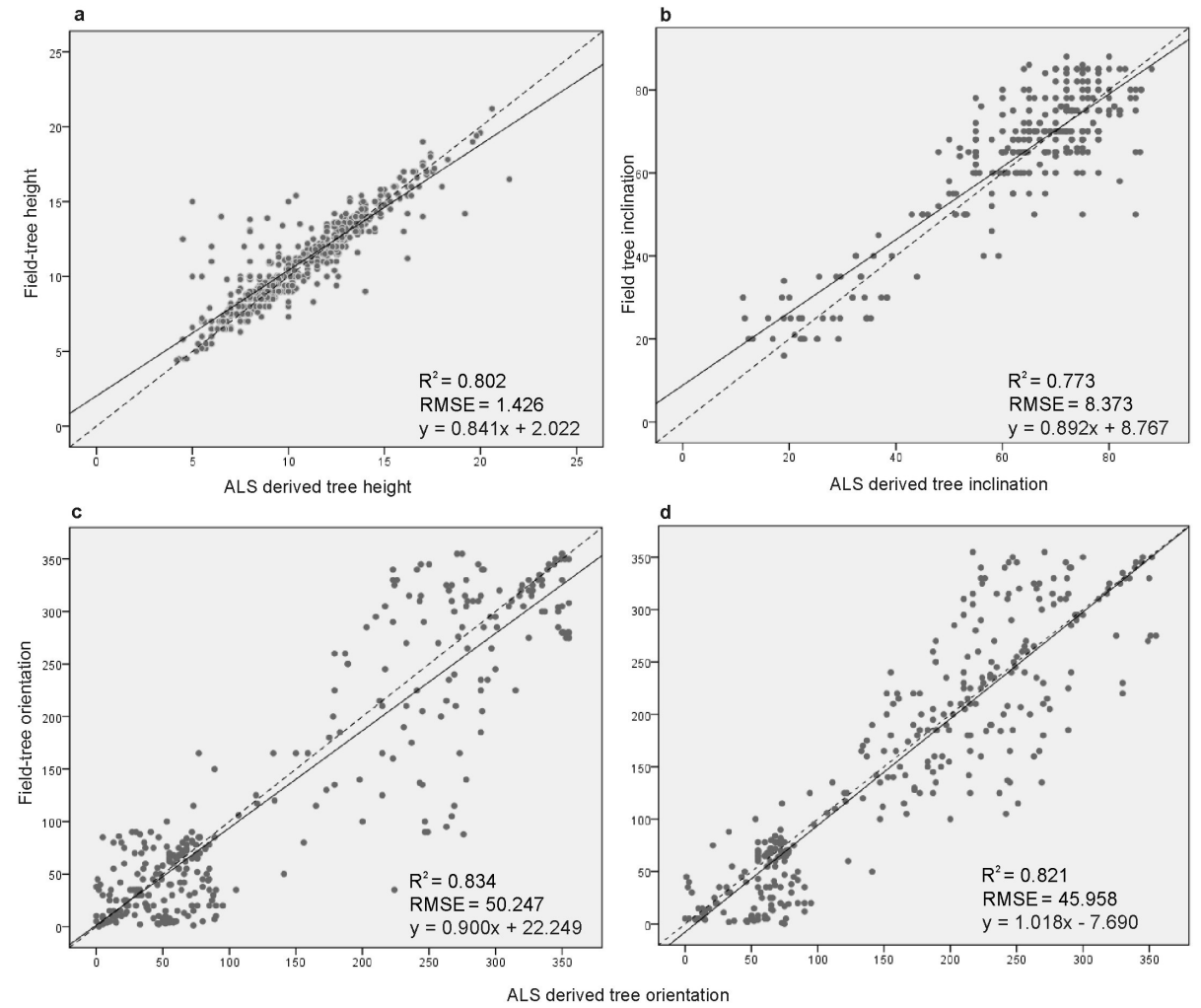

Fig. 1: Scatter plots of ALS-derived tree height, inclination and orientation versus field-derived data in Bois Noir area

The SkelTre-skeletonization method was mostly overpredicting tree inclination $\left(\mathrm{R}^{2}=0.77\right)$ and orientation $\left(\mathrm{R}^{2}=0.83\right)$ across the study area (Fig. 1$)$ in comparison to the ground truth. We also computed the accuracy of two estimated tree orientations (Figs. 1(c)(d)). Here we observed that the predicted tree orientation was more accurate at 1.3 $\mathrm{m}$ trunk height than the estimation at the level of the tree canopy (Fig. 1d). Overall, the SkelTre skeletonization results are very promising given the fact the study area has a large extend, mixed tree species, rugged topographic and characterized by French Alps environment. The challenges work is on the production of high quality of tree delineation and automatic application of the skeletonization approach. The results support the field evidence, which shows a large group of trees in both landslide areas developed relatively low tree height, small crown size and reduced diameter at breast height (DBH), and more inclined and dispersed at different orientation angles, whereas these peculiarities are not so apparent in the undisturbed forests.

The quality of estimated tree irregularity and the number of ALS points recorded on the tree trunk impacts the quality of delineated single trees. Both, the SkelTreskeletonization and the tree delineation rely on the tree geometry represented in the ALS point cloud. For this reason both methods achieved better result in cases where the point density was high enough to represent the stem volume.. However, inaccurate results were derived if the data input had insufficient number of points on the trees especially at the lower tree stem, which showed in some cases only line like point patterns. This factor contributed to large residuals in the tree inclination and orientation predictions. Also, disrupted trees located on steep slopes or areas with a high local surface roughness are marginally hard to delineate and therefore also limit the performance of the SkelTre-skeletonization method.

\subsection{Trees anomaly and landslide activity}

With a $p$-value $<0.05$, the statistical Mann-Whitney $\mathrm{U}$ tests showed all three forest parameters related to landslide disturbances have significant statistical different between each parameter in landslide and non-landslide zones, ranged from 0.001 and $0.015 p$-values. These statistical tests subsequently supported the field observation, which indicates that trees inside the landslide zones have a lower height, dissimilarity in height, and are more inclined and dispersed at different orientation. The results refuted the initial hypothesis that no differences are present. In the more specific study area, trees inclination associated to different landslide kinematic units were analyzed resulting with the $\mathrm{R}^{2}$ ranged between 0.60 and 0.83 [15]. The lower accuracy was found in a landslide transport zone as more displaced materials pass through this narrow zone accompanied by high gradient in both side slopes, leading to peculiarity on morphology, drainage and vegetation.

Single tree analyses revealed that Pinus uncinata had better estimation of tree irregularity due to a competitive advantage of this species over the area that is very dry and 
matrix-poor surface deposit [16]. Landslide processes remained a major factor contributing to the disturbances of forest ecosystem across the study area in the French Alps environment. Morphological and drainage peculiarities also supported the indicator of tree growth disturbances, e.g. in the form of tree height dissimilarity and tree irregularity.

\section{CONCLUSION}

In this study, we showed the utilization of HDALS data for characterizing disrupted trees caused by landslides in a temperate environment. The methods were developed in the Bois Noir area characterized by Callovo-Oxfordian marls in the Barcelonnette Basin (Southern French Alps). The overall results are promising and have the potential to be applied in a tropical mountainous region.

ALS has proven to be a very important new data source for geometric description of complex structural vegetation attributes. With a high point density across the forested landslides, we evaluated the methods to retrieve the vegetation characteristics (tree height, inclination and orientation) associated to growth disturbance, leading to an improved assessment of landslide activity. Field validation data distinctly indicated the signature of tree anomalies in the landslide area compared to the healthy forests.

We concluded that high density ALS is state-of-the-art for geometric retrieval of vegetation structures subjected to forest disturbances (e.g. landslides) in mountainous regions. We believe that leveraging high density ALS as a tool to remotely and non-invasively characterize the tree growth anomalies can detect complex landslides in the near future. Further development of spatiotemporal ALS-derived vegetation characteristics could provide informative clues to landslide activity in a rugged vegetated terrain. With large entropy retrieved from morphological indicators, ALS can be an alternative mapping tool to analyze the reaction (tension and compression) of trees particularly induced by geomorphic processes in a mountainous environment.

\section{REFERENCES}

[1] R. C. Sidle, and H. Ochiai, "Landslides: Processes, Prediction, and Land Use," Water Resources Monograph vol. 18, American Geophysical Union, Washington, 312 pp, 2006.

[2] R. Soeters, and C. J. Van Westen, "Slope Instability Recognition, Analysis, and Zonation," In: Turner AK, Schuster RL (eds) Landslides, Investigation and Mitigation. Transportation Research Board, Special Report 247, Washington, USA, pp. 129177, 1996.

[3] S. Frolking, M. W. Palace, D. B. Clark, J. Q. Chambers, and H. H. Shugart, "Forest Disturbance and Recovery: A General Review in the Context of Spaceborne Remote Sensing on Aboveground Biomass and Canopy Structure," Journal of Geophysical Res. vol. 114, pp. 27, 2009.
[4] M. Parise, "Observation of Surface Features on an Active Landslide and Implications for Understanding its History of Movement," Natural Hazard and Earth System Sciences vol. 3, pp. 569-580, 2003.

[5] M. Van Den Eeckhaut, J. Poesen, G. Verstraeten, V. Vanacker, J. Nyssen, J. Moeyersons, L. P. H. Van Beek, and L. Vandekerckhove, "Use of LIDAR-derived Images for Mapping Old Landslides under Forest," Earth Surface Processes and Landforms vol. 32, pp. 754-769, 2007.

[6] K. A. Razak, M. W. Straatsma, C. J. Van Westen, J. -P. Malet, and S. M. de Jong, "Airborne Laser scanning of Forested Landslides Characterization: Terrain Model Quality and Visualization. Geomorphology vol. 126, pp. 186-200, 2011.

[7] Y. Thiery, J. -P. Malet, S. Sterlacchini, A. Puissant, O. Maquaire, "Landslide susceptibility assessment by bivariate methods at large scales: Application to a complex mountainous environment," Geomorphology 92, 38-59, 2007.

[8] J. -C. Flageollet, O. Maquaire, B. Martin, and D. Weber, "Landslides and climatic conditions in the Barcelonnette and Vars basins (Southern French Alps, France)," Geomorphology 30, 6578, 1999.

[9] O. Maquaire, J. -P. Malet, A. Remaitre, J. Locat, S. Klotz, and J. Guillon, "Instability conditions of marly hillslopes: towards landsliding or gullying? The case of the Barcelonnette Basin, South East France," Engineering Geology 70, 109-130, 2003

[10] J. C. Hippolyte, and T., Dumont, "Identification of Quaternary Thrusts, Folds and Faults in a low seismicity area: examples in the Southern Alps (France)," Terra Nova 12, 156-162, 2002

[11] F. Arnaud, "Documents et notices historiques sur la vallee de Barcelonnette, notice historique sur les torrents de l'Ubaye. Barcelonnette, $1^{\text {st }}$ volume, 1906

[12] J. Lopez Saez, C. Corona, M. Stoffel, L. Astrade, F. Berger, and J. -P. Malet, "Dendrogeomorphic Reconstruction of Past Landslide Reactivation with Seasonal Precision: Bois Noir Landslide, Southern French Alps," Geomorphology, 25 p, 2011

[13] S. C. Popescu, R. H. Wynne, and R. F. Nelson, "Estimating Plot-Level Tree Heights with Lidar: Local Filtering with a CanopyHeight Based Variable Window Size," Computers and Electronics in Agriculture vol. 37, pp. 1-95, 2002.

[14] A. Bucksch, R. Lindenberg and M. Menenti, "Robust Skeleton Extraction from Imperfect Point Clouds," The Visual Computer vol. 26, no. 10, pp. 1283-1300, 2010.

[15] K. A. Razak, A. Bucksch, M. Damen, C. J. Van Westen, M. Straatsma, and S. M. De Jong, "Characterizing tree growth anomaly induced by landslides using LiDAR. Proceedings of the $2^{\text {nd }}$ World Landslide Forum, 3-7 October 2011, Rome, Italy, 2012

[16] H. Mayer, "Wälder des Ostalpenraum," Gustav Fischer Verlag, Stuttgart, Germany, 1974. 